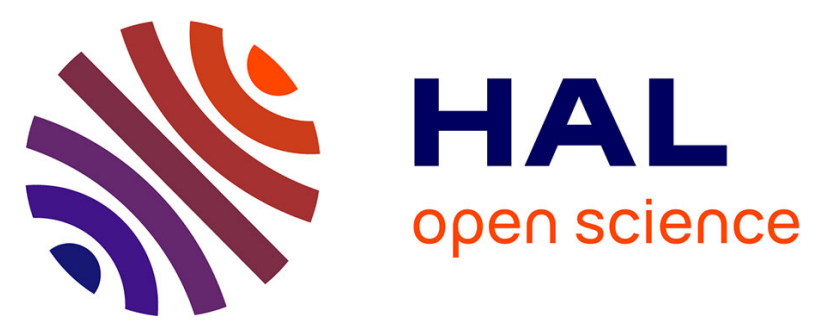

\title{
Current Perception Threshold through Sinusoidal Electrical Stimulation at Different Frequencies in a Comparative Assessment for Subjects Affected and Non-Affected by Diabetes Mellitus
}

\author{
Franassis Oliveira Barbosa, Emerson Fachin-Martins, Clarissa C. S. \\ Couto-Paz, Henrique Martins Resende, Carlos Tierra-Criollo, Christine \\ Azevedo Coste
}

\section{- To cite this version:}

Franassis Oliveira Barbosa, Emerson Fachin-Martins, Clarissa C. S. Couto-Paz, Henrique Martins Resende, Carlos Tierra-Criollo, et al.. Current Perception Threshold through Sinusoidal Electrical Stimulation at Different Frequencies in a Comparative Assessment for Subjects Affected and NonAffected by Diabetes Mellitus. NER: Neural Engineering, Apr 2015, Montpellier, France. pp.906-909, 10.1109/NER.2015.7146772 . lirmm-01384685

\section{HAL Id: lirmm-01384685 \\ https://hal-lirmm.ccsd.cnrs.fr/lirmm-01384685}

Submitted on 20 Oct 2016

HAL is a multi-disciplinary open access archive for the deposit and dissemination of scientific research documents, whether they are published or not. The documents may come from teaching and research institutions in France or abroad, or from public or private research centers.
L'archive ouverte pluridisciplinaire HAL, est destinée au dépôt et à la diffusion de documents scientifiques de niveau recherche, publiés ou non, émanant des établissements d'enseignement et de recherche français ou étrangers, des laboratoires publics ou privés. 


\title{
Current perception threshold through sinusoidal electrical stimulation at different frequencies in a comparative assessment for subjects affected and non-affected by diabetes mellitus
}

\author{
Franassis B. Oliveira, Emerson Fachin-Martins, Clarissa C.S. Couto-Paz, Henrique R. Martins, \\ Member, IEEE, Carlos Julio Tierra-Criollo and Christine Azevedo Coste, Member, IEEE
}

\begin{abstract}
Evidence of Current Perception Threshold (CPT) to assess neural fiber function in healthy subjects suggests greater discrimination for stimuli at 1,250 and $3000 \mathrm{~Hz}$ than at 5, 250 and $2000 \mathrm{~Hz}$. Similar data are not yet described for subjects affected by diabetes mellitus. This study proposes to provide a comparative database of parameters obtained with sinusoidal electrical stimulation applied at 1, 5, 250, 2000 and $3000 \mathrm{~Hz}$ in subjects affected and non-affected by the diabetes. Ninety subjects were recruited to compose the control $(n=45)$ and diabetic $(n=45)$ groups. The CPT intensities and the reaction times obtained for left and right feet stimulation show responses characterized by weaker intensities $(533$ to $1671 \mu \mathrm{A})$ and longer delays (1.24 to $1.42 \mathrm{~s}$ ) at low frequencies (1 and 5 Hz) than the intensities (3965 to $5685 \mu \mathrm{A})$ and delays $(0.96$ to 1.12 s) obtained at high frequencies $(2000$ and $3000 \mathrm{~Hz})$. Moreover, the low frequency stimulation trials evoked up to $73 \%$ of the self-reports corresponding to $\mathrm{C}$-fiber sensations while high frequencies evoked up to $60 \%$ of the self-reports related to Aß-fiber sensations. Moreover, the subjects affected by diabetes needed a stronger intensity of stimulation current in order to perceive consistently the sensations evoked by $A \beta$ fibers (hypoesthesia). In addition, the findings reinforce the suggestion that the discrimination between sensations related to different neural fibers is increased for stimuli at 1,250 and $3000 \mathrm{~Hz}$ for both groups.
\end{abstract}

\section{INTRODUCTION}

Neural fibers can be classified by their size into large or small fibers according to different functions. Large fibers (6 to $12 \mu \mathrm{m}$ ) mediate myotatic reflexes, touch, pressure, vibration and proprioception. Small fibers $(0.2$ to $5 \mu \mathrm{m})$ mediate sensation of temperature and pain, as well

*Research supported by FAPEG-CAPES and MCTI.

E. Fachin-Martins is with the NTAAI - Núcleo de Tecnologia Assistiva, Acessibilidade e Inovação, Faculdade de Ceilândia, Universidade de Brasília, Brasília, Brazil; and with DEMAR team, LIRMM-INRIA, Centre de Recherche Sophia Antipolis Méditerranée, Montpellier, France (corresponding author, phone: 005561 33760252; fax: $00 \quad 5561$ 33760252; e-mail: efmartins@unb.br).

F. B. Oliveira, is with Universidade Estadual de Goiânia, Goiânia; and with Programa de Pós-Graduação em Ciências e Tecnologias em Saúde, Faculdade de Ceilândia, Universidade de Brasília, Brasília, Brazil. (e-mail: franassis_oliveira@yahoo.com.br).

C. C. S. Couto-Paz, is with UnB - Universidade de Brasília, Brasília, Brazil. (e-mail: clarissacardoso@yahoo.com.br).

H. S. Martins, is with Universidade Federal de Minas Gerais, Belo Horizonte, Brazil. (e-mail: henriquerm@gmail.com).

C. J. Tierra-Criollo, is with UFRJ - Universidade Federal do Rio de Janeiro, Rio de Janeiro, Brazil. (e-mail: carjulio@peb.ufrj.br).

C. A. Coste, is with DEMAR team, LIRMM-INRIA, Centre de Recherche Sophia Antipolis Méditerranée, Montpellier, France. (e-mail: christine.azevedo@inria.fr). autonomic function $[\underline{1}, \underline{2}]$. Nerve conduction analyses are breaking new ground by diagnosing and assessing neuropathies and, in particular, the Current Perception Threshold (CPT) - the weakest current intensity capable of evoking a perception - has been reported and suggested as a screening tool to evaluate the damage of the nerve fibers in the peripheral nervous system [프. $\underline{4}]$. In this context, sinusoidal electrical currents can be used at different frequencies to test different fibers and sensations [근 $\underline{5}]$. Martins et al. [5] presented findings obtained from healthy individuals that show better discrimination for stimuli at 1 , 250 and $3000 \mathrm{~Hz}$ than normally applied at 5, 250 and 2000 $\mathrm{Hz}$. Given that the same findings were not present from subjects affected by diabetes mellitus, the primary aim of this study was to provide a comparative database of parameters obtained from sinusoidal electrical stimulation at different frequencies for subjects affected or non-affected (controls) by diabetes mellitus type 2 , allowing a choice of frequencies that would promote better clinical discrimination.

\section{MethodS}

\section{A. Subjects}

Forty-five subjects affected by diabetes mellitus type 2, ages between 56 and 85 years, were recruited to form the diabetic group (table 1). A convenience sampling procedure was performed using subjects who attended a public recruitment forum. Inclusion criteria included: (1) the diagnosis of diabetes mellitus type 2 and (2) a minimal cognition of 19 points evaluated by a modified version of the Mini-mental state examination [6]. All participants presenting other types of disabilities were excluded. Another 45 subjects non-affected by diabetes mellitus were recruited to compose a control group (table 1). All participants ( $\mathrm{n}=90)$ signed a consent form approved by the Research Ethics Committee issued by the Foundation of Education and Research in the Health Sciences, Distrito Federal, protocol number 160.752 .

\section{B. Procedures}

The Michigan Neuropathy Screening Instrument (MNSI) [7] was applied to identify diabetic peripheral neuropathy. In this clinical scoring system, the subject has to reach a score equal or superior to 8 to be diagnosed as diabetic peripheral neuropathy. A NeuroStim System [8] was used to deliver electrical stimulation following the procedures developed by Martins et al. [5]. A sinusoidal current stimulation was applied at frequencies of 1, 5, 250, 2000 and $3000 \mathrm{~Hz}$ to the 
skin over the hallux of the left and right feet for control and diabetic groups. The subjects pressed a button in their dominant hand whenever they felt any somatosensory perception. Such information was used to determine the Current Perception Threshold (CPT) and the Reaction Times (RT).

Just after stimulation sequences, the subjects were asked to describe their perceived sensations in their own words (self-report). Those sensations were classified as small Cfiber sensations (reported by terms like prick, pang, twinge, burn or other similar terms); large $A \beta$-fiber sensations (reported by terms like squeeze, pressure, movement, vibration or other similar terms) or combined sensations. Few subjects had no words to describe their perceptions and were classified as "Not reported" (table 2). In theory, the self-report perceived after a low frequency stimulation (1 and $5 \mathrm{~Hz}$ ) should be associated to C-fiber sensations, whereas that one perceived after a high frequency stimulation $(2000$ and $3000 \mathrm{~Hz}$ ) should be associated to $\mathrm{A} \beta$ fiber sensations. Given that, each self-report presenting the expected association was defined as "consistent perception". The perceptions evoked after $250 \mathrm{~Hz}$ stimulations are mainly related to $A \delta$-fibers and their self-reported terms can be confused with those describing $\mathrm{C}$-fiber and $\mathrm{A} \beta$-fiber sensations. For this reason, A $\delta$-fiber sensations were not considered in this analysis.

The statistical inferences and the graphs were generated by GraphPad Prism 5 and differences were considered when the statistical test resulted in $\mathrm{p}<0.05$. D'Agostino-Pearson test expressed a non-Gaussian distribution for the majority of the variables used in this work. Consequently, we applied a non-parametric test for all analyse.

\section{RESULTS}

A majority, $97.77 \%(n=44)$, in the control group and $95.55 \%(n=43)$ in the diabetic group were composed of women. Both groups included overweight senior participants (25.00 < BMI < 29.99) with preserved cognition (MMS > 19 points) as observed in table 1 . The diabetic group did not presented any subject diagnosed as diabetic peripheral neuropathy, including MNSI scores ranging from 0 to 6 points (MNSI < 8).

TABLE I. CHARACTERISTICS OF THE NON-AFFECTED (CONTROL) AND AFFECTED (DIABETIC) GROUPS

\begin{tabular}{|c|c|c|c|c|}
\hline Characteristics & \multicolumn{2}{|c|}{ Control } & \multicolumn{2}{|c|}{ Diabetic } \\
\hline Age (years) & \multicolumn{2}{|c|}{$65.89 \pm 5.65$} & \multicolumn{2}{|c|}{$68.51 \pm 6.82$} \\
\hline $\operatorname{BMI}\left(\mathrm{kg} / \mathrm{m}^{2}\right)$ & \multicolumn{2}{|c|}{$25.89 \pm 3.79$} & \multicolumn{2}{|c|}{$26.27 \pm 6.72$} \\
\hline MMS (points) & \multirow{2}{*}{\multicolumn{2}{|c|}{$\begin{array}{l}26.84 \pm 3.01 \\
\text { Not Applied }\end{array}$}} & \multirow{2}{*}{\multicolumn{2}{|c|}{$\begin{aligned} 25.67 & \pm 3,39 \\
4.27 & \pm 4.04\end{aligned}$}} \\
\hline MNSI (points) & & & & \\
\hline $\operatorname{CPT}(\mu \mathrm{A})$ & left & right & left & right \\
\hline $1 \mathrm{~Hz}$ & $533.00 \pm 272.60$ & $571.00 \pm 312.50$ & $631.50 \pm 356.30$ & $678.10 \pm 426.20$ \\
\hline $5 \mathrm{~Hz}$ & $1127.00 \pm 610.80$ & $1248.00 \pm 717.90$ & $1671.00 \pm 1213.00$ & $1218.00 \pm 676.20$ \\
\hline $250 \mathrm{~Hz}$ & $2064.00 \pm 904.10$ & $1882.00 \pm 801.80$ & $2058.00 \pm 1092.00$ & $2316.00 \pm 1520.00$ \\
\hline $2000 \mathrm{~Hz}$ & $3965.00 \pm 1273.00$ & $4444.00 \pm 1534.00$ & $4397.00 \pm 987.40$ & $4830.00 \pm 1062.00$ \\
\hline $3000 \mathrm{~Hz}$ & $4622.00 \pm 1270.00$ & $4896.00 \pm 1522.00$ & $5194.00 \pm 1062.00$ & $5685.00 \pm 1132.00$ \\
\hline RT (s) & left & right & left & right \\
\hline $1 \mathrm{~Hz}$ & $1.31 \pm 0.43$ & $1.42 \pm 0.42$ & $1.24 \pm 0.32$ & $1.38 \pm 0.44$ \\
\hline $5 \mathrm{~Hz}$ & $1.36 \pm 0.39$ & $1.38 \pm 0.42$ & $1.41 \pm 0.43$ & $1.40 \pm 0.34$ \\
\hline $250 \mathrm{~Hz}$ & $1.03 \pm 0.39$ & $1.14 \pm 0.48$ & $1.16 \pm 0.41$ & $1.16 \pm 0.38$ \\
\hline $2000 \mathrm{~Hz}$ & $0.99 \pm 0.29$ & $1.12 \pm 0.47$ & $0.98 \pm 0.28$ & $1.04 \pm 0.28$ \\
\hline $3000 \mathrm{~Hz}$ & $1.00 \pm 0.30$ & $1.02 \pm 0.32$ & $0.96 \pm 0.29$ & $0.96 \pm 0.19$ \\
\hline
\end{tabular}

Values are presented by mean \pm the Standard Deviation (SD). Wilcoxon Matched-Pairs Signed Rank Test did not detect significant differences $(p>0.05)$ between controls and diabetic groups. The comparisons were made between the control and diabetic groups for all frequencies (1, 5, 250, 2000 and $3000 \mathrm{~Hz}$ ) and sides (left and right): BMI - Body Mass Index; MMS - Mini-Mental Score; MNSI - Michigan Neuropathy Screening Instrument; CPT - Current Perception Threshold and RT - Reaction Time.

\section{A. Perceptions self-reported}

In table 2, we observe a larger contingent of consistent perceptions for 1 than $5 \mathrm{~Hz}$ stimulations in the left feet from the control group. For the diabetic group, the contingent of consistent perceptions obtained from $1 \mathrm{~Hz}$ was $9 \%$ less than that obtained from $5 \mathrm{~Hz}$ stimulation just in the left feet. Comparing the contingent of consistent perceptions observed in high frequency stimulations, we found a higher contingent of consistent perceptions from 3000 than $2000 \mathrm{~Hz}$ in the right feet for both groups.

\begin{tabular}{|c|c|c|c|c|c|c|c|}
\hline \multirow{2}{*}{ TABLE II. } & PROI & \multirow[b]{3}{*}{ Side } & \multirow{2}{*}{\multicolumn{5}{|c|}{$\frac{\text { RTED PERCEPTIO }}{\text { Frequencies }}$}} \\
\hline & erceptions & & & & & & \\
\hline Groups & Sensations & & $1 \mathrm{~Hz}$ & $5 \mathrm{~Hz}$ & $250 \mathrm{~Hz}$ & $2000 \mathrm{~Hz}$ & $3000 \mathrm{~Hz}$ \\
\hline \multirow{8}{*}{$\left.\mathrm{S}^{5}\right]$} & \multirow[b]{2}{*}{ C-fiber } & left & 个 $73 \%$ & $58 \%$ & $60 \%$ & $53 \%$ & $49 \%$ \\
\hline & & right & $73 \%$ & $71 \%$ & $78 \%$ & $56 \%$ & $42 \%$ \\
\hline & \multirow{2}{*}{$A \beta$-fiber } & left & $22 \%$ & $42 \%$ & $38 \%$ & $47 \%$ & $51 \%$ \\
\hline & & right & $27 \%$ & $27 \%$ & $22 \%$ & $42 \%$ & † $56 \%$ \\
\hline & \multirow{2}{*}{ Combined } & left & $4 \%$ & $0 \%$ & $2 \%$ & $0 \%$ & $0 \%$ \\
\hline & & right & $0 \%$ & $2 \%$ & $0 \%$ & $0 \%$ & $2 \%$ \\
\hline & \multirow{2}{*}{ Not reported } & left & $0 \%$ & $0 \%$ & $0 \%$ & $0 \%$ & $0 \%$ \\
\hline & & right & $0 \%$ & $0 \%$ & $0 \%$ & $2 \%$ & $0 \%$ \\
\hline \multirow{8}{*}{\begin{tabular}{l|l}
100 \\
1 & $\vdots$ \\
1 & $\vdots$
\end{tabular}} & \multirow{2}{*}{ C-fiber } & left & $\downarrow 62 \%$ & $71 \%$ & $49 \%$ & $51 \%$ & $56 \%$ \\
\hline & & right & $67 \%$ & $73 \%$ & $60 \%$ & $60 \%$ & $36 \%$ \\
\hline & \multirow{2}{*}{$A \beta$-fiber } & left & $33 \%$ & $27 \%$ & $49 \%$ & $47 \%$ & $40 \%$ \\
\hline & & right & $33 \%$ & $24 \%$ & $40 \%$ & $38 \%$ & $460 \%$ \\
\hline & \multirow{2}{*}{ Combined } & left & $2 \%$ & $0 \%$ & $0 \%$ & $0 \%$ & $0 \%$ \\
\hline & & right & $0 \%$ & $2 \%$ & $0 \%$ & $2 \%$ & $0 \%$ \\
\hline & \multirow{2}{*}{ Not reported } & left & $2 \%$ & $2 \%$ & $2 \%$ & $2 \%$ & $4 \%$ \\
\hline & & right & $0 \%$ & $0 \%$ & $0 \%$ & $0 \%$ & $4 \%$ \\
\hline
\end{tabular}

Values are presented for each group by percentages of the sample separated in columns by frequencies $(1,5,250$, 2000 and $3000 \mathrm{~Hz}$ ). The images of the feet differentiate the control (drawn in dark lines) from the diabetic (drawn in light lines) group. Kinds of sensations were divided by their relationship with $\mathrm{C}$ or $\mathrm{A} \beta$ fibers from the left and right foot (lines). The significant increases $(\uparrow)$ or decreases $(\downarrow)$ of the self-reported contingents indicating a consistent perception were indicated by arrows. The significant discrepancies $(p<0.05)$ were detected between the proportions observed from stimulations at 1 and $2000 \mathrm{~Hz}$ when, respectively, compared to the proportions expected from stimulations at 5 and $3000 \mathrm{~Hz}$ by the Chi-Square Test.

\section{B. Sinusoidal electrical stimulation at different frequencies}

As observed in figure 1, the CPT intensities at low frequency stimulations ( 1 and $5 \mathrm{~Hz}$ ) generally demanded weaker intensities than those at higher frequencies $(2000 \mathrm{~Hz}$ and $3000 \mathrm{~Hz}$ ). The intensities of the stimulations applied at 1 $\mathrm{Hz}$ were significantly different from the intensities observed at 250, 2000 and $3000 \mathrm{~Hz}$ in all experimental conditions. Furthermore, from the right foot of the diabetic group, the 
intensity of the $\mathrm{CPT}$ at $1 \mathrm{~Hz}$ was also different from the intensity observed at $5 \mathrm{~Hz}$ (figure 1).

The same did not occur for intensities observed from the $5 \mathrm{~Hz}$ stimulations. As observed in figure 1, there were significant differences from intensities at 2000 and $3000 \mathrm{~Hz}$, but they were not different from those observed at $250 \mathrm{~Hz}$. In addition, for all experimental conditions, we did not find differences among the pairs of intensities obtained between $2000 \mathrm{~Hz}$ and $3000 \mathrm{~Hz}$.

Despite the fact that the statistical test for matched-pairs did not find significant differences between control and diabetic groups (table 1) for CPT intensities, a significant variance of means was detected between the control and diabetic groups for CPT applied at 2000 and $3000 \mathrm{~Hz}$ and the multiple comparison post-test identified significant increase between the left foot of the control group and the right foot of the neuropathic group, as indicated by the arrows in figure 1 .

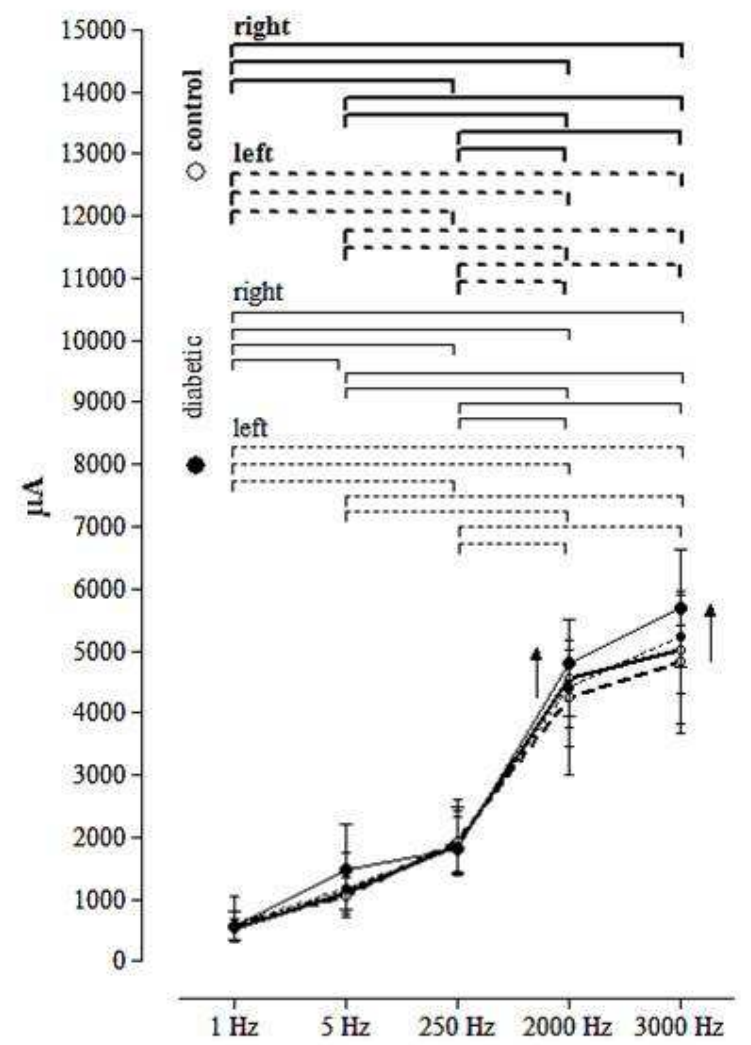

Figure 1. Connecting-lines graph indicating median and interquartile range for the intensities of Current Perception Threshold (CPT) analyzed at different frequencies $(1,5,250,2000$ and $3000 \mathrm{~Hz})$. The CPT intensities were grouped from non-affected (control $\circ-$ thick lines) and affected (diabetic • - fine lines) subjects considering right (continuous lines) and left (discontinuous lines) body sides. The significant differences - detected from Kruskal-Wallis Test followed for Dunn's Multiple Comparison PostTest and considering $\mathrm{p}<0.05$ - are presented together with the legend (upper graph area) by indicative lines linking pairs of frequencies. The significant increases observed for the diabetic groups - detected by the same statistical test - were indicated by arrows $(\uparrow)$
As observed in figure 2, in general, the RT at low frequency stimulations ( 1 and $5 \mathrm{~Hz}$ ) were longer than those at higher frequencies $(2000$ and $3000 \mathrm{~Hz}$ ). The delay to perceive the stimulations applied at $1 \mathrm{~Hz}$ were significantly different from those observed at 2000 and $3000 \mathrm{~Hz}$ in all experimental conditions. Furthermore, from both feet of the control group (right and left sides), the delay of the RT at $1 \mathrm{~Hz}$ was also different from the delay observed at $250 \mathrm{~Hz}$. However, none difference of delay was observed between 1 and $5 \mathrm{~Hz}$ (figure 2).

The same occurs to the delays observed from $5 \mathrm{~Hz}$ stimulations, including a significant difference observed between 5 and $250 \mathrm{~Hz}$ for the right foot from the diabetic group. The delays at 2000 and $3000 \mathrm{~Hz}$ were significantly different from those observed at 1 and $5 \mathrm{~Hz}$, but were not different from those observed at $250 \mathrm{~Hz}$ in all experimental conditions (figure 2).

In addition, for all experimental conditions (figure 2), we did not find differences among the pairs of delays obtained between $2000 \mathrm{~Hz}$ and $3000 \mathrm{~Hz}$.

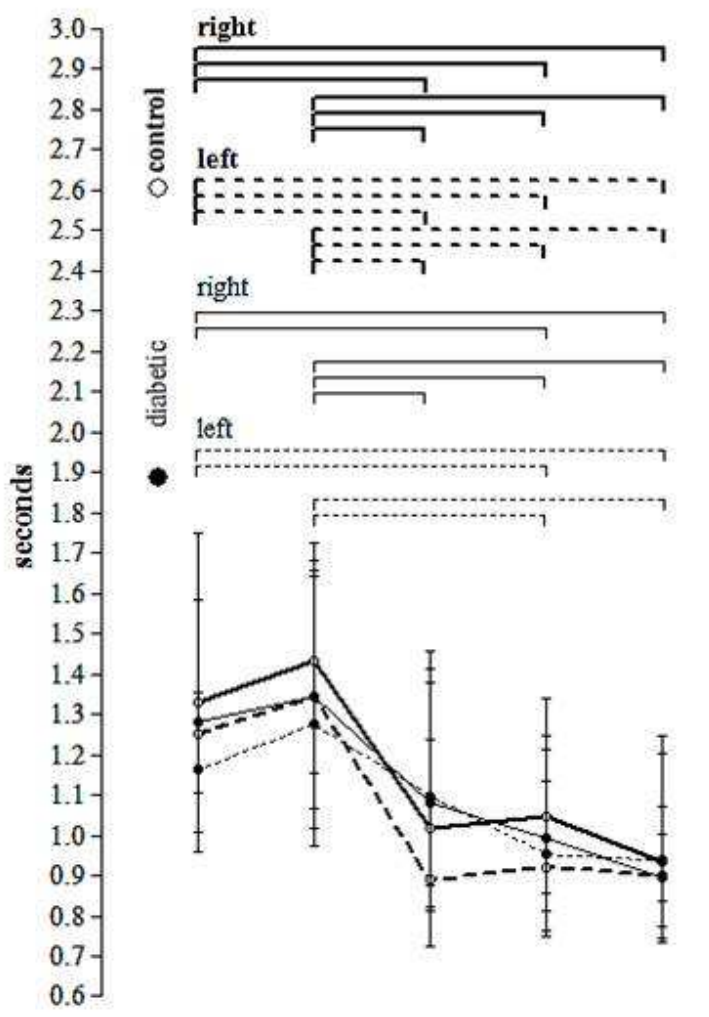

$1 \mathrm{~Hz} \quad 5 \mathrm{~Hz} \quad 250 \mathrm{~Hz} \quad 2000 \mathrm{~Hz} \quad 3000 \mathrm{~Hz}$

Figure 2. Connecting-lines graph indicating median and interquartile range for the reaction time (RT) delays analyzed in different frequencies ( 1 , 5, 250, 2000 and $3000 \mathrm{~Hz}$ ). The RT delays were grouped from non-affected (control $\bigcirc-$ thick lines) and affected (diabetic $\bullet$ - fine lines) subjects considering right (continuous lines) and left (discontinuous lines) body sides. The significant differences - detected from Kruskal-Wallis Test followed for Dunn's Multiple Comparison Post-Test and considering $\mathrm{p}<0.05$ - were also presented together with the legend (upper graph area) by indicative lines linking pairs of delays. 


\section{DISCUSSION}

As previously observed by Martins et al. [ $\underline{5}, \underline{8}]$, this study showed the same pattern of stimulation characterized by weaker CPT intensities and longer RT delays at low frequencies $(1$ and $5 \mathrm{~Hz}$ ) than the intensities and delays at high frequencies $(2000$ and $3000 \mathrm{~Hz})$. Moreover, the stimulation at $250 \mathrm{~Hz}$ presented intermediate intensities and delays. Koester and Sielgelbaum [9] explain that the small fibers have a more increased capacitance than the large fibers, then the low frequency stimulations promote depolarization of the small fibers whereas the high frequency stimulation do the same for large fibers. The middle frequency stimulations should have an intermediate behavior.

For the control group, more numerous contingents of consistent perceptions were found for 1 and $3000 \mathrm{~Hz}$ than 5 and $2000 \mathrm{~Hz}$ stimulations, reinforcing that a better discrimination is found at these frequencies as previously suggested [ $\underline{5}, \underline{8}]$. As the non-affected group, the group affected by diabetes presented almost the same proportions of self-reports, apart from a consistent perception reduced to $9 \%$ in the left foot during $1 \mathrm{~Hz}$ stimulations (table 2). In addition, a kind of left-right-footedness was observed in the self-reports.

As concluded by Tan [10], an asymmetric organization interhemispheric of the somatosensory potentials evoked by stimulations of the left and right sides could contribute to a consistent perception more lateralized due to stronger sensory feedback correlated with a hand preference. However, we did not conducted tests to identify hand and foot preferences for further discussion, a limitation of this study.

Although the subjects affected by the diabetes had similar age, gender proportion, body composition, stimulation parameters, and delay of perception than the non-affected subjects (table 1), an increased intensity of current was applied to evoke sensations at 2000 and $3000 \mathrm{~Hz}$ (figure 1) for the diabetic group, identifying an hypoesthesia [11] in the A $\beta$-fibers which was not clinically detected by the MNSI [7] (4.27士4.04). This result supports a possible advantage to early diagnosis of the diabetic peripheral neuropathy commonly developed in this population.

\section{CONCLUSION}

The comparative data in this study showed that the subjects affected by the diabetes mellitus needed a higher intensity of stimulation to perceive the sensations evoked by A $\beta$-fibers (hypoesthesia). In addition, the findings suggest greater dissimilarities obtained for stimuli at 1,250 and 3000 $\mathrm{Hz}$ than 5, 250 and $2000 \mathrm{~Hz}$, reinforcing their use for both groups.

\section{ACKNOWLEDGMENT}

We thank A. R. Bezerra, D. I. Oliveira-Azevedo and K.K.P. Botelho - the undergraduates in physical therapy of the University of Brasilia and State University of Goias - for their support during the experimental procedures to collect the data. We also thank A. P. Murray for the English review.

\section{REFERENCES}

[1] N. Papanas and D. Ziegler, "New diagnostic tests for diabetic distal symmetric polyneuropathy," J Diabetes Complications., vol. 25, pp. 44-51. doi: 10.1016/j.jdiacomp.2009.09.006. Epub 2009 Nov 6., 2011.

[2] G. Said, "Diabetic neuropathy," Handb Clin Neurol., vol. 115:579_ 89., pp. 10.1016/B978-0-444-52902-2.00033-3., 2013.

[3] A. Nather, et al., "Assessment of sensory neuropathy in patients with diabetic foot problems," Diabet Foot Ankle., vol. 2., p. 10.3402/dfa.v2i0.6367. Epub 2011 Jun 16., 2011.

[4] W. Zheng, et al., "Correlation of current perception threshold and somatosensory evoked potential in diabetes," Neurophysiol Clin., vol. 42, pp. 241-7. doi: 10.1016/j.neucli.2012.02.136. Epub 2012 Mar 17., 2012.

[5] H. R. Martins, et al., "Current perception threshold and reaction time in the asssessment of sensory peripheral nerve fibers through sinusoidal electrical stimulation at different frequencies," Brazilian Journal of Biomedical Engineering, vol. 29, pp. 278-285, 2013.

[6] M. Folstein, "Mini-mental and son," Int J Geriatr Psychiatry., vol. 13, pp. 290-4., 1998.

[7] A. Moghtaderi, et al., "Validation of Michigan neuropathy screening instrument for diabetic peripheral neuropathy," Clin Neurol Neurosurg., vol. 108, pp. 477-81. Epub 2005 Sep 16., 2006.

[8] H. R. Martins, "Sistema para estudo do limiar de percepção de corrente elétrica com forma de onda arbitrária," Master Dissertation, Engineering Biomedical, Universidade Federal de Minas Gerais, Belo Horizonte, 2008

[9] J. Koester and S. A. Siegelbaum, "Local signaling passive electrical properties of the neuron," in Principles of neural science, E. R. Kandel, et al., Eds., ed New York: McGraw-Hill, 2000, pp. 140-149.

[10] U. Tan, "Cerebral somatosensory potentials evoked by posterior tibial nerve stimulation: lateralization and relation to handedness in lefthanded normal subjects," Int J Neurosci., vol. 49, pp. 303-17., 1989.

[11] A. Hohne, et al., "Reduced plantar cutaneous sensation modifies gait dynamics, lower-limb kinematics and muscle activity during walking," Eur J Appl Physiol., vol. 112, pp. 3829-38. doi: 10.1007/s00421-012-2364-2. Epub 2012 Mar 6., 2012. 